\title{
Suivi de croissance de Penicillium camemberti et Geotrichum candidum en culture pure et en association au cours de l'affinage de fromages expérimentaux à pâte molle de type camembert
}

\author{
P Molimard 1, L Vassal 2, I Bouvier 3, HE Spinnler ${ }^{1}$ \\ ${ }^{1}$ Laboratoire de recherches sur les arômes, INRA, BV 1540, F-21034 Dijon cedex; \\ 2 Station de recherches laitières, INRA, F-78352 Jouy-en-Josas cedex; \\ ${ }^{3}$ Sanofi Bio-Industries, division Cultures \& enzymes, 66, avenue Marceau, F-75008 Paris, France
}

(Reçu le 20 juillet 1994 ; accepté le 3 novembre 1994)

\begin{abstract}
Résumé - La cinétique de croissance de Penicillium camemberti (4 souches) et de Geotrichum candidum ( 3 souches) a été suivie, tout au long de l'affinage, sur des fabrications expérimentales de camemberts. Elle a nécessité la mise au point d'une méthode de dénombrement spécifique de ces 2 espèces en culture mixte sur un milieu modèle et sur des camemberts du commerce. Geotrichum candidum se développe fortement pendant la première semaine d'affinage. Le niveau de population se stabilise par la suite. La population de Penicillium camemberti reste au niveau d'ensemencement pendant les 7 premiers jours, puis augmente jusqu'au $14^{e}$ jour. Pendant les 2 dernières semaines d'affinage, le nombre de cellules revivifiables de Penicillium camemberti est alors constant. La présence de Geotrichum candidum ne change pas de façon significative le niveau de population de Penicillium camemberti. En revanche, un effet souche Penicillium camemberti et Geotrichum candidum est mis en évidence.
\end{abstract}

Penicillium camemberti / Geotrichum candidum / culture mixte / dénombrement / camembert

Summary - Growth of Penicillium camemberti and Geotrichium candidum in pure and mixed cultures on experimental mold ripened cheese of camembert-type. The growth of Penicillium camemberti ( 4 strains) and Geotrichum candidum ( 3 strains) was followed during the ripening on experimental camembert cheeses. A method permitting to enumerate both species on a model medium and on camembert cheese was set up. Geotrichum candidum growth is fast for the first ripening week. Then the level of population is more stable. For the first week no growth of Penicillium camemberti is observed, the population then grew until the 14th day. During the last 2 weeks of ripening the number of living cells is constant. The growth of Geotrichum candidum has no significant effect on the growth of Penicillium camemberti. On the other hand, an effect of the Penicillium camemberti strain on Geotrichum candidum strain was observed.

Penicillium camemberti / Geotrichum candidum / mixed culture / enumeration / camembert cheese 


\section{INTRODUCTION}

La consommation de fromages à pâte molle et à croûte fleurie, plus particulièrement de camembert, représente une part importante du marché du fromage. Les qualités organoleptiques de ces produits sont très variables et parfois mal maîtrisées dans les fabrications traditionnelles au lait cru. La technologie de fabrication, à partir de lait pasteurisé, apporte une plus grande reproductibilité, mais on déplore alors une baisse de l'intensité et de la complexité aromatique des produits. Les caractères organoleptiques du camembert apparaissent suite à d'importantes modifications des constituants du caillé sous l'action des enzymes du lait, de la présure et des micro-organismes qui peuplent le fromage (Adda et al, 1982). La flore microbienne de camemberts obtenus à partir de laits pasteurisés est relativement pauvre et se limite essentiellement aux seuls micro-organismes ajoutés pendant la fabrication (Tolle et al, 1980). Dans les fabrications au lait cru, la flore est naturellement plus complexe (Lenoir et Auberger, 1966). Geotrichum candidum fait partie de la flore naturellement présente dans les fabrications au lait cru (Richard et Zadi, 1983 ; Jean, 1989). Longtemps, on a cherché à éviter le développement de ce champignon levuriforme quit, mal maîtrisé, est susceptible de provoquer un défaut d'aspect de la croûte, appelé «peau de crapaud". Pourtant, son rôle important dans l'amélioration des qualités organoleptiques des fromages a été démontré (Mourgues et al, 1983 ; Ribadeau-Dumas, 1984 ; Molimard et al, 1994). Ces auteurs ont montré que Geotrichum candidum peut réduire fortement l'amerture et renforcer la flaveur des fromages sans en modifier l'aspect. Afin d'obtenir des produits typés, de manière reproductible, ce qui correspond à une demande des consommateurs, les industriels s'orientent vers l'utilisation d'une flore plus complexe. La maítrise de cette flore nécessite une meilleure connaissance d'une part, des caractéristiques de croissance des souches en mélanges, d'autre part de l'impact de cette flore sur le développement de la texture et de la flaveur.

L'objectif de notre étude est de suivre le développement de Penicillium camemberti et de Geotrichum candidum en association, au cours de l'affinage de fromages expérimentaux, de type camembert, à flore définie. A cause des difficultés posées par le dénombrement de champignons filamenteux en mélange (Jarvis et al, 1983), très peu de travaux ont été réalisés jusqu'à présent sur la quantification de ces 2 espèces en fromagerie. Mourgues et al (1983), dans leur étude, ont dénombré uniquement la population de Geotrichum candidum sur des camemberts expérimentaux. Ils ont suivi le développement de Penicillium camemberti par une simple observation de la surface des fromages. La première étape de notre travail a donc consisté à mettre au point une méthode d'estimation de la biomasse de Penicillium camemberti et de Geotrichum candidum en mélange, fiable, reproductible et simple à mettre en œuvre. II existe actuellement diverses techniques appliquées à la détection de champignons contaminants des denrées alimentaires (Frankland et Lindley, 1978; Cousin et al, 1984 ; Lin et Cousin, 1985 ; Notermans et Heuveiman, 1985 ; Lin et al, 1986 ; Notermans et al, 1986 ; Kamphuis et al, 1989 ; Notermans et Kamphuis, 1990). Ces techniques, le plus souvent immunologiques, ne sont pas quantitatives. Frankland et al (1981) ont développé une technique immunologique permettant de quantifier la biomasse mycélienne de Mycena galopus dans de l'humus. Cette technique, très spécifique, est lourde à mettre en œuvre. Elle nécessite d'isoler un antigène spécifique de l'espèce à quantifier, ce qui est relativement difficile. La production, chez le lapin, d'un anticorps monoclonal dirigé contre cet antigène est une autre étape longue et délicate. D'autres 
techniques plus simples mais moins spécifiques existent (Jarvis et al, 1983), telles que le comptage des propagules après broyage et dilution de l'échantillon à étudier. C'est cette technique qui ne dénombre que les cellules vivantes, que nous avons retenue. Après avoir mis au point un milieu sélectif pour chacune des 2 espèces, les paramètres de broyage de l'échantillon (temps, vitesse de rotation du broyeur, dilution de l'échantillon) ont été optimisés sur des cultures en milieu synthétique et sur fromages, afin de définir des conditions répétables permettant une meilleure quantification de la biomasse. Ensuite, nous avons suivi la croissance de ces 2 champignons lorsqu'ils se développent en association, d'une part en milieu liquide afin de tester notre méthode de dénombrement, puis au cours de l'affinage de fromages expérimentaux.

\section{MATÉRIEL ET MÉTHODES}

\section{Matériel biologique}

Quatre souches de Penicillium camemberti (Pc1, $\mathrm{Pc2}, \mathrm{Pc}, \mathrm{Pc} 4)$ et 3 souches de Geotrichum candidum (Gc1, Gc2, Gc3) ont été utilisées. Le code $\mathrm{GcO}$ est utilisé pour signaler l'absence de Geotrichum candidum dans les fromages. Ces souches proviennent de la collection de la société Sanofi Bio-Industries, division Cultures et enzymes (Paris, France).

Deux souches de Lactococcus lactis subsp cremoris, provenant de la collection du CNRZ (INRA-SRL, Jouy-en-Josas, France), ont été utilisées lors des fabrications fromagères : la souche $1139 \mathrm{G}$ (Prot $\left.{ }^{+}\right)$et la souche $1140 \mathrm{P}$ (Prot).

\section{Cultures sur milieu liquide}

La biomasse a été obtenue à partir d'une culture de 21 jours sur milieu liquide PDB (Difco Laboratories, Detroit, États-Unis) en erlenmeyer de $500 \mathrm{ml}$ contenant $150 \mathrm{ml}$ de milieu. L'ensemen- cement de ces cultures a été réalisé avec une suspension de spores obtenue à partir d'une culture de 21 jours en fioles de Roux sur milieu gélosé PDA (Merck, Darmstadt, Allemagne) à raison de $2,5 \cdot 10^{3}$ spores de Penicillium camemberti et $2,5 \cdot 10^{1}$ spores de Geotrichum candidum par $\mathrm{ml}$ de milieu.

L'optimisation de la méthode de broyage a été effectuée sur des culots cellulaires obtenus après centrifugation pendant $10 \mathrm{~min}$ à $16300 \mathrm{~g}$ de cocultures des souches Pc4 et Gc1 incubées 14 j à $24^{\circ} \mathrm{C}$. Le poids des culots cellulaires a été déterminé par pesées.

L'évolution de la biomasse des cocultures et des cultures pures des souches Pc4 et Gc1 en milieu liquide a été suivie au cours du temps. Pour cela, 6 fioles ont été prélevées aux temps 0 , $3,6,9,14,21$ et 28 jours d'incubation à $12^{\circ} \mathrm{C}$. $\dot{A}$ chaque prélèvement, 3 fioles ont été réservées au dénombrement des UFC après broyage et les 3 autres fioles à la mesure du poids sec après dessication à $101^{\circ} \mathrm{C}$ du mycélium filtré sur filtre Millipore ${ }^{\circledR}$, diamétre de pores de $0,45 \mu \mathrm{m}$ (Millipore corporation, Bedford, MA, États-Unis).

Les taux de croissance $(\mu)$, au temps t, ont été déterminés par la relation suivante, où $X$ représente le nombre d'unités formant colonies (UFC) par ml :

$$
\begin{gathered}
\mu_{t}=\left(1 / X_{t}\right)\left[\left(X_{t}-X_{t-1}\right) /\left(t-t_{1}\right)+\left(X_{t+1}-X_{t}\right)\right. \\
\left./\left(t_{+1}-t\right)\right](1 / 2)
\end{gathered}
$$

\section{Broyages des échantillons}

Le culot cellulaire, ou le fromage, ont été broyés, après dilution avec de l'eau physiologique stérile $(0,9 \%$ de $\mathrm{NaCl})$, dans un pot en verre d'un volume de $100 \mathrm{ml}$. Trois paramètres de broyage, susceptibles d'influencer directement le nombre des UFC dénombrées après étalement du broyat sur les milieux sélectifs, ont été optimisés : la vitesse de rotation du broyeur Ultra-turrax ${ }^{\oplus 25}$ équipé d'une sonde de broyage S25N-18G (IKA-Labortechnick, Staufen, Allemagne), exprimée en nombre de rotations par minute (rpm), le temps de broyage en secondes, la concentration en biomasse de la suspension à broyer exprimée en facteur de dilution. La vitesse du broyeur peut être régulée entre 8000 et $24000 \mathrm{rpm}$. Quant au temps de broyage, des essais préliminaires ont montré qu'en dessous de $10 \mathrm{~s}$ l'échantillon 
n'est pas homogène et au-delà de $35 \mathrm{~s}$, il y a formation d'une mousse trop abondante.

Ces facteurs ont été étudiés selon un plan d'expériences central composite permettant de tester l'influence de chacun d'eux et leurs interactions, en optimisant le nombre des essais à réaliser (Goupy, 1988). Pour chacun des facteurs, 3 niveaux ont été fixés dans les limites imposées par le matériel utilisé :

- $X=$ vitesse de rotation du broyeur : 10500 , $13500,16500 \mathrm{rpm}$;

$-Y=$ temps de broyage : 10, 20, 30 s ;

$-Z$ = dilution du culot cellulaire : $0,25,0,5,0,75$.

La matrice d'expériences comprend 23 points nécessaires à l'étude des 3 facteurs à 3 niveaux. La variabilité a été déterminée sur le point central du domaine expérimental $(13500 ; 20 ; 0,5)$, répété 9 fois. Les points aux sommets du cube forment le domaine expérimental. Six points sont situés à l'extérieur du domaine expérimental $(8$ $450 ; 20 ; 0,5),(18540 ; 20 ; 0,5),(13500 ; 3 ;$ $0,5),(13500 ; 37 ; 0,5),(13500 ; 20 ; 0,08),(13$ $500 ; 20 ; 0,92$ ).

Le broyat a été dilué dans de l'eau physiologique stérile, de 10 en 10 . Les dilutions comprises entre $10^{-1}$ et $10^{-4}$ ont été étalées sur 3 boîtes de Pétri de $100 \mathrm{~mm}$ de diamètre de chacun des 2 milieux sélectifs. Le nombre moyen d'UFC sur les 3 boîtes a été retenu.

\section{Milieux sélectifs}

Penicillium camemberti a été cultivé sélectivement sur milieu gélosé composé de $50 \mathrm{~g}^{\circ-1}$ de PDA (Merck) ; $75 \mathrm{mg}^{\circ-1}$ de Chloramphénicol (France Biochem, Meudon, France) ; $6 \%$ de $\mathrm{NaCl}$ (Prolabo, Paris, France). Les boites de Pétri ont été incubées 6 jours à $20^{\circ} \mathrm{C}$. En effet, Penicillium camemberti est particulièrement résistant au sel, la plupart des souches ne sont complètement inhibées qu'à partir de $25 \%$ de $\mathrm{NaCl}$ dans le milieu. En milieu solide, des teneurs de 1 à $2 \%$ favorisent sa croissance. Sa température optimale de développement sur extrait de malt est comprise entre 20 et $25^{\circ} \mathrm{C}$; à $30^{\circ} \mathrm{C}$ sa croissance est fortement réduite. II ne pousse plus à $37^{\circ} \mathrm{C}$ (Cerning et al, 1987).

Geotrichum candidum a été cultivé sélectivement sur milieu gélosé PDA (Merck) (50 g $\left.{ }^{-1}\right)$, Chloramphénicol (France Biochem) (75 $\left.\mathrm{mg}^{\circ} \mathrm{I}^{-1}\right)$ dépourvu de $\mathrm{NaCl}$. Les boîtes de Pétri ont, dans ce cas, été incubées 3 jours à $30^{\circ} \mathrm{C}$. Geotrichum est, en effet, très sensible au sel. Son inhibition se manifeste entre 1 et $2 \%$ de $\mathrm{NaCl}$ dans le milieu. La température optimale de croissance pour les souches feutrantes est située entre 25 et $30^{\circ} \mathrm{C}$ (Guéguen, 1984 ; Guéguen et Schmidt, 1992).

Le Chloramphénicol a été stérilisé séparément par filtration sur filtre stérilisant Millipore ${ }^{\circledR}$, diamètre de pores de 0,2 $\mu \mathrm{m}$ (Millipore corporation, Bedford, MA, États-Unis). Il a été ajouté au milieu après autoclavage afin de permettre l'élimination ou le ralentissement de la plupart des bactéries.

\section{Fabrication des fromages}

Quarante litres de lait, standardisé à $28 \%$ de matière grasse et pasteurisé $18 \mathrm{~s}$ à $72^{\circ} \mathrm{C}$, ont été utilisés pour obtenir un lot de 20 fromages. Le lait, refroidi à $35^{\circ} \mathrm{C}$, a été inoculé immédiatement à $2 \%$ avec un mélange contenant $5 \%$ d'une culture sur lait autoclavé de Lactococcus lactis Prot+ (souche $1139 \mathrm{G}$ ) et $95 \%$ d'une culture de Lactococcus lactis Prot (souche $1140 \mathrm{P}$ ).

Les suspensions de spores de Penicillium camembertiet Geotrichum candidum ont été ajoutées au lait avant l'emprésurage, à raison de 2500 spores $/ \mathrm{ml}$ environ ( $99 \%$ de Penicillium camemberti et $1 \%$ de Geotrichum candidum lorsque ces 2 espèces ont été utilisées en association). L'emprésurage a été réalisé avec 15 $\mathrm{ml} / 100$ I de lait, de présure Granday ${ }^{\circ}$ à $520 \mathrm{mg} /$ de chymosine (Sanofi Bio-Industries, Paris, France). Le temps de coagulation était d'environ $40 \mathrm{~min}$. Le caillé a été découpé lorsque le $\mathrm{pH}$ atteignait $6,1 \pm 0,1$ puis moulé grâce à un dispositif permettant le retournement des bassines. Les moules ont été retournés 2 fois pendant l'égouttage, la première à $\mathrm{pH} 5,5 \pm 0,9$ et la seconde à $\mathrm{pH} 4,9 \pm 0,1$. Le lendemain les fromages ont été salés en saumure saturée, pendant $40 \mathrm{~min}$ à $15^{\circ} \mathrm{C}$. Les fromages ont ensuite été maintenus $24 \mathrm{~h}$ à $15^{\circ} \mathrm{C}$ et $85 \%$ d'humidité relative, puis affinés à $12^{\circ} \mathrm{C}$ et $95 \%$ d'humidité relative. Ils ont été emballés à l'áge de 12 jours et placés ensuite à $8^{\circ} \mathrm{C}$ et $85 \%$ d'humidité relative pendant deux semaines.

Chaque souche de Penicillium camemberti a été utilisée seule et en association avec les 3 souches de Geotrichum candidum, soit 16 produits. Leur fabrication a été répétée 4 fois. Pour chacune des répétitions de fabrication des 16 
produits (variable "produit"), un fromage a été prélevé a $7,14,21$ et 28 jours d'affinage (variable "jour") afin de dénombrer les populations de Penicillium camemberti et Geotrichum candidum.

Une fabrication supplémentaire a été réalisée dans le but d'étudier les premiers jours d'affinage. Quatre produits ont alors été fabriqués avec $\mathrm{Pc2}$ (Pc2* Gc0, Pc2*Gc1, Pc2*Gc2, Pc2*Gc3). Un fromage a été prélevé à $1,2,6,7,9,14,21$ et 28 jours d'affinage). Des fromages ont également été prélevés à $1,2,6,7,9,14,21$ et 28 jours d'affinage d'une fabrication réalisée avec l'association des souches $\mathrm{Pc} 2$ et $\mathrm{Gc} 2$, mais à raison de $5 \%$ de $\mathrm{Gc} 2$.

\section{Analyses statistiques}

Toutes les analyses statistiques ont été menées sur le logiciel SAS ${ }^{\oplus}$ (SAS Institute Inc, Cary, NC, États-Unis). La planification des expériences (plan central composite et plan complet) ainsi que l'ordre aléatoire de réalisation des essais, afin de tenir compte des facteurs non contrôlés pouvant influencer les réponses mesurées, ont étē déterminés par les macros ADX.

Les résultats obtenus après réalisation du plan d'expériences central composite ont été explorés par un test d'analyse de la variance sur les 3 facteurs : temps, vitesse et dilution. Une analyse de régression a été réalisée par la procédure RSREG de SAS/STAT ${ }^{\oplus}$ (1989).

Les résultats obtenus après réalisation des plans d'expériences complets ont été explorés par une analyse de variance à 2 facteurs (temps et vitesse) au moyen de la procédure GLM de SAS/STAT (1989) ainsi que par une analyse de la régression par la procédure RSREG de SAS/STAT ${ }^{\circ}$ (1989)

Les résultats des dénombrements au cours de l'affinage des fromages expérimentaux ont été soumis à une analyse de variance à 2 facteurs (produit et jour) et interaction. Une analyse de variance sur les facteurs Penicillium camemberti et Geotrichum candidum et interaction a également été réalisée.

Les représentations graphiques (figs 3,4 et 5) ont été obtenues grâce au programme Charter sur SAS ${ }^{\star}$ (P Schlich, INRA-LRSA, Dijon, France).

\section{RÉSULTATS ET DISCUSSION}

\section{Mise au point de la méthode de broyage}

Dans un premier temps, nous avons réalisé un plan d'expériences à 3 facteurs (temps, vitesse de rotation du broyeur, dilution de l'échantillon) et 3 niveaux pour définir les conditions qui permettent d'optimiser le dénombrement.

L'analyse de la régression montre que, globalement, ce modèle explique seulement $29,8 \%$ de la variabilité totale observée (dont $20,1 \%$ sont expliqués par l'effet linéaire des facteurs et $9,2 \%$ par les interactions d'ordre 2). L'effet des facteurs étudiés n'est pas significatif $(P>0,05)$. La dilution et les interactions d'ordre 2 entre les facteurs possèdent les effets les moins marqués sur la mesure.

Compte tenu de la très faible contribution du modèle à l'explication de la variabilité, l'étude des facteurs temps et vitesse de rotation du broyeur a été affinée par la réalisation d'un plan complet d'expériences répété trois fois. Ce protocole permet d'évaluer la variabilité sur chacun des points. Le domaine expérimental a été redéfini par rapport aux résultats obtenus précédemment :

$-X=$ vitesse $: 12000,18000,24000 \mathrm{rpm}$; $-Y=$ temps : $15,25,35 \mathrm{~s}$.

La biomasse a été diluée 4 fois. L'espace expérimental est alors formé par 9 points.

Pour Penicillium camemberti, le Log des UFC/ml est compris entre $5,6 \pm 0,2$ après 15 $\mathrm{s}$ de broyage à $24000 \mathrm{rpm}$ et $6,2 \pm 0,1$ après $25 \mathrm{~s}$ à $24000 \mathrm{rpm}$.

Le Log du nombre d'UFC/ml de Geotrichum candidum est situé entre $5,3 \pm 0,2$ pour $15 \mathrm{~s}$ à $24000 \mathrm{rpm}$ et $5,6 \pm 0,2$ pour $25 \mathrm{~s}$ à $24000 \mathrm{rpm}$ (tableau I).

L'étude de la régression et de l'analyse de la variance montre que le modèle étudié explique $54,3 \%$ de la variabilité pour 
Tableau I. Population de Penicillium camemberti (Pc4) et Geotrichum candidum (Gc1) dénombrée après broyage de culots cellulaires obtenus par culture en milieu liquide. Log du nombre d'UFC/ml de culot cellulaire, moyenne de 3 broyages.

Population of Penicillium camemberti (PC4) and Geotrichum candidum (Gc1) enumerated after grinding of cell pellets obtained by culture in liquid medium. Log of the number of CFU/g of cell pellet, mean of 3 grindings.

\begin{tabular}{|c|c|c|c|c|}
\hline \multirow{2}{*}{$\begin{array}{c}\text { Temps } \\
\text { (s) }\end{array}$} & \multirow[t]{2}{*}{ Espèce 1} & \multicolumn{3}{|c|}{ Vitesse de broyage (rpm) } \\
\hline & & 12000 & 18000 & 24000 \\
\hline 15 & $\begin{array}{l}\mathrm{Pc} \\
\mathrm{Gc}\end{array}$ & $\begin{array}{l}5,8 \pm 0,1 \\
5,3 \pm 0,1\end{array}$ & $\begin{array}{l}5,9 \pm 0,3 \\
5,3 \pm 0,4\end{array}$ & $\begin{array}{l}5,6 \pm 0,2 \\
5,3 \pm 0,2\end{array}$ \\
\hline 25 & $\begin{array}{l}\mathrm{Pc} \\
\mathrm{Gc}\end{array}$ & $\begin{array}{l}5,8 \pm 0,2 \\
5,5 \pm 0,1\end{array}$ & $\begin{array}{l}5,8 \pm 0,3 \\
5,5 \pm 0,1\end{array}$ & $\begin{array}{l}6,2 \pm 0,1 \\
5,6 \pm 0,2\end{array}$ \\
\hline 35 & $\begin{array}{l}\mathrm{Pc} \\
\mathrm{Gc}\end{array}$ & $\begin{array}{l}6,0 \pm 0,3 \\
5,6 \pm 0,1\end{array}$ & $\begin{array}{l}5,9 \pm 0,2 \\
5,6 \pm 0,2\end{array}$ & $\begin{array}{l}5,9 \pm 0,2 \\
5,5 \pm 0,2\end{array}$ \\
\hline
\end{tabular}

1 Pc : Penicillium camemberti ; Gc : Geotrichum candidum.

Penicillium camemberti et $32,9 \%$ pour Geotrichum candidum. Dans cette part de la variabilité expliquée par les facteurs testés, la contribution du facteur temps de broyage est de $16,9 \%$ pour Penicillium camembertiet de $83,7 \%$ pour Geotrichum candidum et celle de la vitesse de broyage est de $1 \%$ pour Penicillium camemberti et $2,3 \%$ pour Geotricum candidum. L'interaction temps x vitesse contribue à cette variabilité au niveau de $82,1 \%$ pour Penicillium camemberti et $14 \%$ pour Geotrichum candidum. Cependant, pour les 2 facteurs, l'effet sur le Log UFC/ml des 3 niveaux testés n'est pas significatif $(P>0,05)$.

Le même plan d'expérience a été réalisé sur des camemberts au lait cru du commerce. Pour cela, $25 \mathrm{~g}$ de fromage ont été broyés dans $50 \mathrm{ml}$ d'eau physiologique stérile.

On a ainsi dénombré entre $4,7 \pm 0,3 \mathrm{Log}$ UFC/g après $15 \mathrm{~s}$ de broyage à $18000 \mathrm{rpm}$
Tableau II. Population de Penicillium camemberti (Pc4) et Geotrichum candidum (Gc1) dénombrée après broyage de $25 \mathrm{~g}$ de fromage. Log du nombre d'UFC/g de fromage, moyenne de 3 broyages.

Population of Penicillium camemberti (PC4) and Geotrichum candidum (Gc1) enumerated after grinding. $\mathrm{Log}$ of the number of CFU/g of cheese, mean of 3 grindings.

\begin{tabular}{|c|c|c|c|c|}
\hline \multirow{2}{*}{$\begin{array}{c}\text { Temps } \\
\text { (s) }\end{array}$} & \multirow[t]{2}{*}{ Espèce $^{1}$} & \multicolumn{3}{|c|}{ Vitesse de broyage (rpm) } \\
\hline & & 12000 & 18000 & 24000 \\
\hline \multirow[t]{2}{*}{15} & $\mathrm{Pc}$ & $6,7 \pm 0,2$ & $6,6 \pm 0,1$ & $6,6 \pm 0,2$ \\
\hline & Gc & $5,1 \pm 0,5$ & $4,7 \pm 0,3$ & $4,9 \pm 0,4$ \\
\hline \multirow[t]{2}{*}{25} & $\mathrm{Pc}$ & $6,6 \pm 0,3$ & $6,6 \pm 0,3$ & $6,8 \pm 0,4$ \\
\hline & Gc & $5,1 \pm 0,3$ & $4,9 \pm 0,5$ & $4,9 \pm 0,6$ \\
\hline \multirow[t]{2}{*}{35} & $\mathrm{Pc}$ & $6,7 \pm 0,2$ & $6,7 \pm 0,3$ & $6,5 \pm 0,2$ \\
\hline & Gc & $5,1 \pm 0,7$ & $4,9 \pm 0,9$ & $4,8 \pm 1,0$ \\
\hline
\end{tabular}

1 Pc : Penicillium camemberti; Gc: Geotrichum candidum.

et $5,1 \pm 0,3 \mathrm{Log}$ UFC/g après $25 \mathrm{~s}$ à 12000 rpm pour Geotrichum candidum. La population de Penicillium camemberti est comprise entre $6,5 \pm 0,2 \mathrm{Log}$ UFC/g après 35 $s$ à $24000 \mathrm{rpm}$ et $6,8 \pm 0,4 \mathrm{Log}$ UFC/g après $25 \mathrm{~s}$ à $24000 \mathrm{rpm}$ (tableau II). II n'y a pas de différence significative $(P>0,05)$ entre les 3 niveaux de vitesse de broyage $(12000,18000,24000 \mathrm{rpm})$ et de durée de broyage $(15,25,35 \mathrm{~s})$ testés.

Au vu des résultats précédents, il s'avère que lorsque les conditions de broyage permettent d'obtenir une homogénéisation correcte de l'échantillon à dénombrer, il y a peu de modification du nombre d'UFC dans le domaine expérimental étudié. Nous avons donc retenu les conditions de $25 \mathrm{~s}$ à 18000 rpm, qui sont des conditions moyennes donnant une bonne homogénéité de l'échantillon. Ces conditions seront celles employées pour tous les dénombrements 
de la flore de surface des camemberts expérimentaux que nous avons analysés, ainsi que des cultures en milieu liquide.

\section{Suivi des populations de Penicillium camemberti et Geotrichum candidum en milieu liquide}

\section{En cultures pures}

La teneur en matière sèche (MS) des cultures de Geotrichum candidum (Gc1) augmente progressivement jusqu'à un maximum de $4,73 \pm 0,19 \mathrm{mg} / \mathrm{ml}$ au $14 \mathrm{e}$ jour. Elle chute ensuite très légèrement jusqu'à $4,0 \pm$ $0,09 \mathrm{mg} / \mathrm{ml}$ en fin de culture (fig 1 ). Paral-

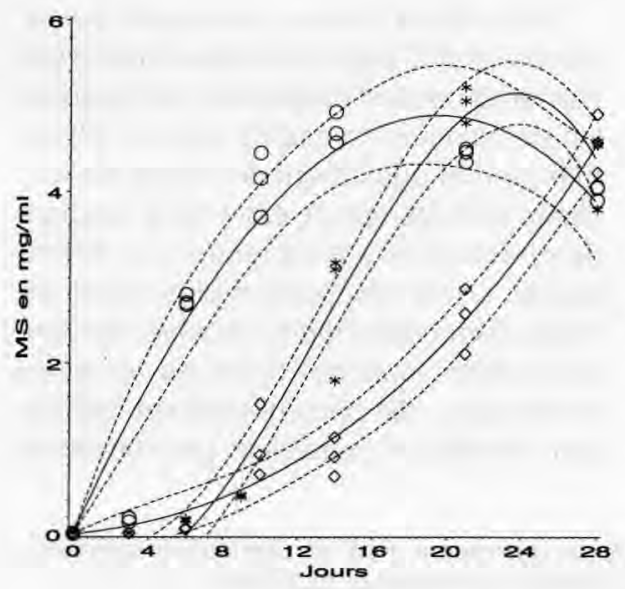

Fig 1. Évolution de la matière sèche (MS en $\mathrm{mg} / \mathrm{ml}$ ) des cultures pures et des cocultures en milieu liquide de Geotrichum candidum (Gc1) et de Penicillium camemberti (Pc4). * Coculture; $\mathrm{O}$ culture pure de Geotrichum candidum; $\oslash$ culture pure de Penicillium camemberti.

Evolution of the dry matter (MS in $\mathrm{mg} / \mathrm{ml}$ ) of pure and coculture in liquid medium of Geotrichum candidum (Gc1) and Penicillium camemberti (PC4). *, Coculture; $O$, pure culture of Geotrichum candidum; $\diamond$, pure culture of Penicillium camemberti. lèlement, le nombre d'UFC/ml croît rapidement jusqu'au $10^{e}$ jour de culture $\left(3,0 \cdot 10^{7}\right.$ $\mathrm{UFC} / \mathrm{ml}$ ) avant de se stabiliser à ce niveau (fig 2). La corrélation entre le Log du nombre d'UFC/ml et le Log de la teneur en matière sèche des cultures est hautement significative $(r=0,98 ; P=0,0001 ; d d l=20)$. Le dénombrement des UFC donne donc une bonne estimation de la biomasse.

Penicillium camemberti (Pc4) se développe beaucoup plus lentement et atteint une teneur en matière sèche de $4,57 \pm 0,34$ $\mathrm{mg} / \mathrm{ml}$ après 28 jours (fig 1 ). Cette biomasse est comparable à celle de Geotrichum candidum après 14 jours de culture malgré un ensemencement en Penicillium camemberti 100 fois plus important que celui de Geotrichum candidum. Le nombre d'UFC/ml

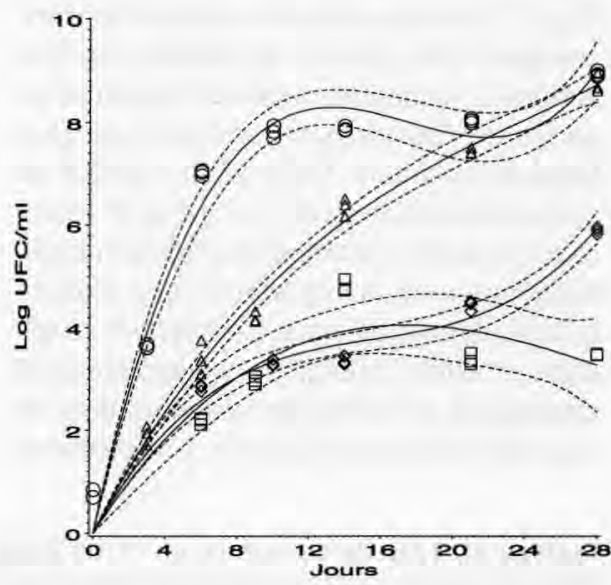

Fig 2. Évolution du Log d'UFC par ml de cultures pures et de cocultures de Penicillium camemberti (Pc4) et de Geotrichum candidum (Gc1). $\diamond$ Penicillium camemberti en culture pure ; $\square$ Penicillium camemberti en coculture ; O Geotrichum candidum en culture pure ; $\Delta$ Geotrichum candidum en coculture.

Evolution of the Log of CFU of pure cultures and cocultures of Penicillium camemberti (Pc4) and Geotrichum candidum (Gc1). 0 , Penicillium camemberti in pure culture $\square$, Penicillium camemberti in coculture; $\mathrm{O}$, Geotrichum candidum in pure culture; $\Delta$, Geotrichum candidum in coculture. 
dénombré évolue parallèlement à la teneur en matière sèche. La corrélation entre le Log de ces 2 modes d'expression de la biomasse est là aussi hautement significative $(r=0,81 ; P=0,0003 ; d d l=14)$. Là aussi, par le dénombrement des UFC, nous avons une estimation correcte de la biomasse.

\section{En cultures mixtes}

Le taux de matière sèche, dans les cultures, augmente progressivement jusqu'à un maximum de $5,03 \pm 0,21 \mathrm{mg} / \mathrm{ml}$ de culture au $21^{e}$ jour. II diminue par la suite jusqu'à $4,31 \pm 0,45 \mathrm{mg} / \mathrm{ml}$ de culture au $28^{\mathrm{e}}$ jour (fig 1). Le nombre d'UFC de Geotrichum candidum (Gc1) par ml de culture augmente régulièrement tout au long des 28 jours de culture et atteint un maximum de $5,5 \cdot 10^{8}$ (fig 2). Cette population maximum est comparable à celle obtenue en culture pure. Sur la figure 2, il apparaît clairement que la croissance de Geotrichum candidum est plus faible en coculture. Cependant, les taux de croissance (tableau III) à 9,14 et 21 jours, calculés sur le nombre d'UFC/ml sont significativement plus importants en coculture qu'en culture pure pour Geotrichum candidum. En effet, à 9 jours de cultures pures, la croissance est presque terminée, donc le taux de croissance est faible. En revanche, en cultures mixtes la croissance continue jusqu'en fin de culture.

Le nombre d'UFC de Penicillium camemberti (Pc4) par $\mathrm{ml}$ de culture augmente á partir du $6^{\mathrm{e}}$ jour jusqu'à un maximum de $6,5 \cdot 10^{4}$ au $14^{e}$ jour, il diminue par la suite (fig 2). Penicillium camemberti se développe plus rapidement pendant les premiers jours en cultures mixtes, mais son développement se stabilise rapidement, alors qu'en culture pure il se développe tout au long des 28 jours de culture. Au $9^{e}$ jour, le taux de croissance (tableau III) est significativement plus important en coculture qu'en culture pure. À 14 et 21 jours, le taux de croissance devient significativement plus important en culture pure. Peut-être que cette stimulation ne s'exprime qu'avant épuisement du glucose.

Cette étude montre clairement que le nombre d'UFC estimé en milieu liquide, par notre méthode, est directement lié à la quantité de biomasse présente dans le milieu. Elle permet également de mettre en évidence une interaction, entre les 2 souches de chacune des 2 espèces, sur milieu liquide. Le développement plus rapide de Penicillium camemberti, observé pendant les premiers jours de cocultures sur milieu synthétique, est particulièrement intéressant. En effet, en fromagerie, une couverture

Tableau III. Taux de croissance en $\mathrm{j}^{-1}$ de Penicillium camemberti (Pc4) et Geotrichum candidum (Gc1) en culture pure et coculture en milieu liquide, calculé sur le nombre d'UFC/ml.

Growth rate in day-1 of Penicillium camemberti (Pc4) and Geotrichum candidum (Gc1) in pure culture and coculture in liquid medium calculated with the number of CFU/mI

\begin{tabular}{|c|c|c|c|c|}
\hline \multirow[t]{2}{*}{ Jours } & \multicolumn{2}{|c|}{ Penicillium camemberti } & \multicolumn{2}{|c|}{ Geotrichum candidum } \\
\hline & Cocultures & Culture pure & Cocultures & Culture pure \\
\hline 6 & & & $1,3 \pm 0,8$ & $1,4 \pm 0,7$ \\
\hline 9 & $7,1 \pm 2,2$ & $0,1 \pm 0,0$ & $4,6 \pm 3,4$ & $0,1 \pm 0,0$ \\
\hline 14 & $0,1 \pm 0,0$ & $0,8 \pm 0,3$ & $0,9 \pm 0,3$ & $0,1 \pm 0,0$ \\
\hline 21 & $-1,9 \pm 0,7$ & $2,1 \pm 0,8$ & $1,5 \pm 0,4$ & $0,4 \pm 0,3$ \\
\hline
\end{tabular}


plus précoce du fromage est particulièrement recherchée pour une compétition plus forte et plus précoce avec les éventuels contaminants d'une part et pour un affinage plus rapide d'autre part. Or il semble que la souche de Penicillium camemberti Pc4 et la souche de Geotrichum candidum Gc1, lorsqu'elles se développent ensemble sur ce milieu synthétique, ont une croissance plus rapide. De plus, Geotrichum candidum se développe plus tôt que Penicillium camemberti, pouvant ainsi assurer une occupation plus précoce du milieu.

II n'existe pas de grande différence entre les populations finales des cultures pures et des cultures mixtes (fig 2). Ce qui veut dire que le nombre total d'UFC de Penicil-

Tableau IV. Différence de viabilité spécifique, exprimée en Log d'UFC/mg de matière sèche (MS), entre les cultures pures et les cultures mixtes.

Change in specific viability, expressed as Log of CFU/mg of dry matter (MS), between pure cultures and mixed cultures.

\begin{tabular}{rrrr} 
Jours & $\begin{array}{c}\text { Log UFC/mg MS } \\
\text { Culture pure } \\
\text { (1) }\end{array}$ & $\begin{array}{c}\text { Culture mixte } \\
\text { (2) }\end{array}$ & $\begin{array}{c}\text { Coefficient } \\
\text { de viabilité } \\
\text { (2)/(1) }\end{array}$ \\
\hline & & & \\
14 & 2,53 & 17,10 & 7,00 \\
21 & 1,39 & 2,25 & 1,62 \\
28 & 1,16 & 1,48 & 1,27 \\
& 1,03 & 2,02 & 1,96 \\
\end{tabular}

\footnotetext{
${ }^{1} \mathrm{Log}$ UFC/mg MS = Log [(UFC de Geotrichum candidum en culture pure) + (UFC de Penicillium camemberti en culture pure)]/ [(MS de Geotrichum candidum en culture pure) + (MS de Penicillium camemberti en culture pure)]. ${ }^{2}$ Log UFC/mg MS = Log [(UFC de Geotrichum candidum en culture mixte) + (UFC de Penicillium camembertien culture mixte)]/(MS de la culture mixte). 1 Log CFU/mg MS = Log [(CFU of Geotrichum candidum in pure culture) + (CFU of Penicillium camemberti in pure culture)] / [(MS of Geotrichum candidum in pure culture) + (MS of Penicillium camemberti in pure culture)]. ${ }^{2} \log$ CFU/mg MS $=\log$ ([CFU of Geotrichum candidum in mixed culture) + (CFU of Penicillium camemberti in mixed culture)] / (MS of the mixed culture).
}

lium camemberti et de Geotrichum candidum est supérieur en cultures mixtes à celui des cultures pures. Or la quantité de matière sèche en cultures mixtes est plus faible que la somme des matières sèches des cultures pures de Penicillium camemberti et de Geotrichum candidum. II y a donc plus de cellules viables par unité de matière sèche en cultures mixtes qu'en cultures pures (tableau IV). II y a également plus de cellules viables par unité de matière sèche en début de culture qu'en fin de culture. Cependant, la forte viabilité du mycélium en culture pure à 6 jours $(17,10 \mathrm{Log}$ UFC/mg MS) peut être due à une imprécision de la mesure de la matière sèche qui est à un niveau faible à ce stade de culture. Ces résultats peuvent laisser penser qu'en cocultures l'activité métabolique globale est plus intense qu'en culture pure, puisque la viabilité de la biomasse semble plus importante. II reste à savoir si ce qui est observé sur milieu modèle est également vrai sur fromage. Ceci pourrait laisser supposer un affinage plus rapide en culture mixte.

\section{Suivi des populations de Penicillium camemberti et Geotrichum candidum en fabrications fromagères expérimentales}

La population de Penicillium camembertiau $7^{e}$ jour d'affinage, pour les 4 souches, est significativement plus faible $(P<0,05)$ que celle présente après 14 jours. Au contraire, il n'y a aucune différence significative $(P$ ) $0,05)$ entre les dénombrements effectués à 14,21 et 28 jours. L'interaction produit ${ }^{\star}$ jours n'est pas signifiative $(P>0,05)$, ce qui signifie que le classement du nombre moyen d'UFC des 4 souches de Penicillium camemberti reste le même tout au long de l'affinage. La population de la souche Pc1 est significativement plus importante que celle de $\mathrm{Pc2}$ et $\mathrm{Pc3}$ au seuil de $0,2 \%$, pour toutes les associations confondues (fig 3 ). 


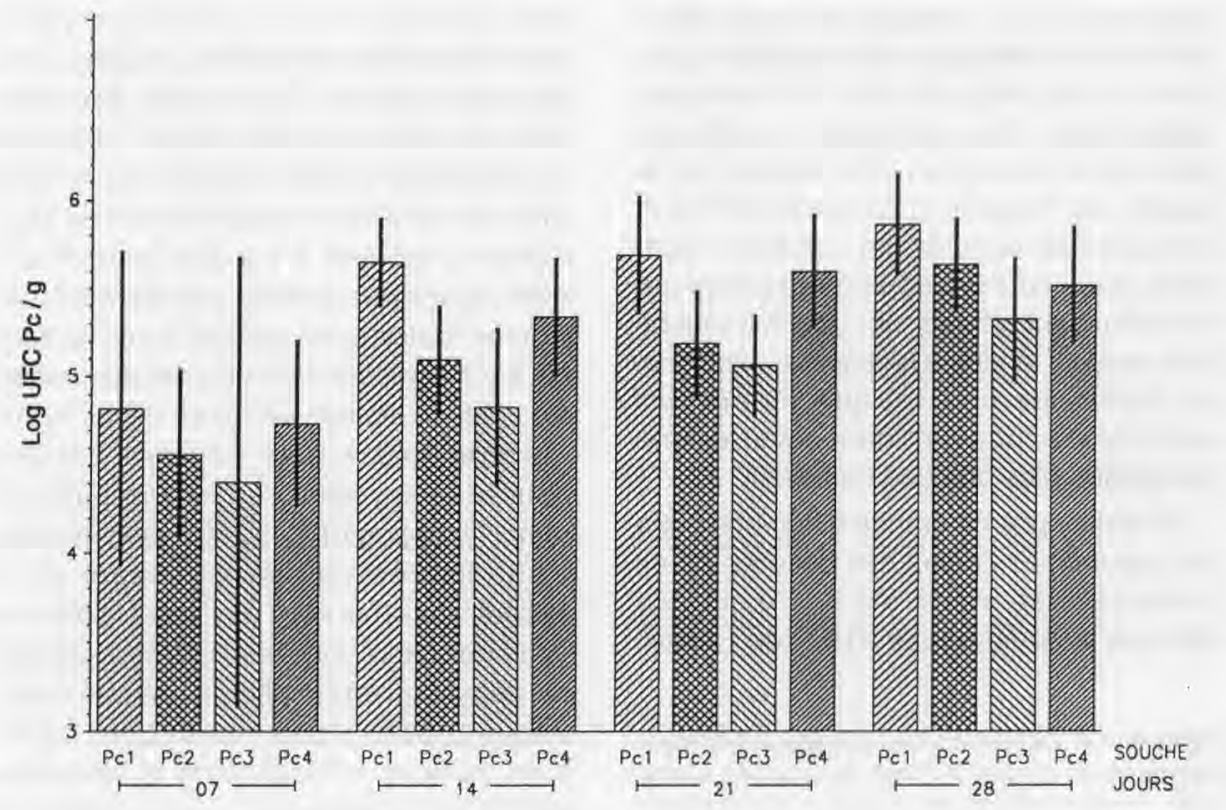

Fig 3. Évolution de la population des 4 souches de Penicillium camembertiau cours de l'affinage des fromages. Log UFC Pc/g : Log UFC Penicillium camemberti par gramme de fromage frais, moyenne des 4 produits fabriqués 4 fois, soit 16 mesures. Souche : souche de Penicillium camemberti. Jours : nombre de jours d'affinage. Les barres verticales représentent l'intervalle de confiance à $95 \%$.

Change in the population of the four Penicillium camemberti strains during cheeses ripening. Log UFC PC/g: Log CFU of Penicillium camemberti per $g$ of fresh cheese, mean of the 4 products and 4 cheese making replicates (16 measures). Souche: Penicillium camemberti strains. Jours: number of ripening days. The vertical line represents the confidence interval at the level of $95 \%$.

La population de Penicillium camemberti n'est pas significativement différente $(P>$ $0,05)$ en présence ou non de Geotrichum candidum, quelle que soit la souche de Penicillium camemberti. Un exemple est montré figure 4 , avec la souche Pc4. Pourtant, l'observation de la surface des fromages révèle des aspects différents en présence de Geotrichum candidum, et ceci en fonction des souches. Ces différences d'aspects sont très certainement imputables aux caractéristiques de développement des souches de Geotrichum candidum (souches plus ou moins feutrantes).

Pour les 4 produits dont les UFC ont été dénombrées en début d'affinage, la population de la souche Pc2 est constante pen- dant les 7 premiers jours à $3,6 \pm 0,1$ Log UFC/g. La croissance débute après 7 jours et la population se stabilise au $14^{e}$ jour à $5,2 \pm 0,5 \mathrm{Log}$ UFC/g. Malgré cette stabilité du nombre d'UFC, l'observation de la surface des fromages montre une importante évolution de la couverture mycélienne après le $14^{e}$ jour. Cela peut s'expliquer par le fait que notre méthode ne dénombre que les cellules revivifiables. On peut penser qu'une partie du mycélium est constituée de cellules non revivifiables, qui ne sont donc pas dénombrées. Le nombre des cellules revivifiables serait constant au-delà de 14 jours.

La population de Geotrichum candidum, pour les 3 souches étudiées, n'est pas différente entre les 3 prélèvements effectués à 


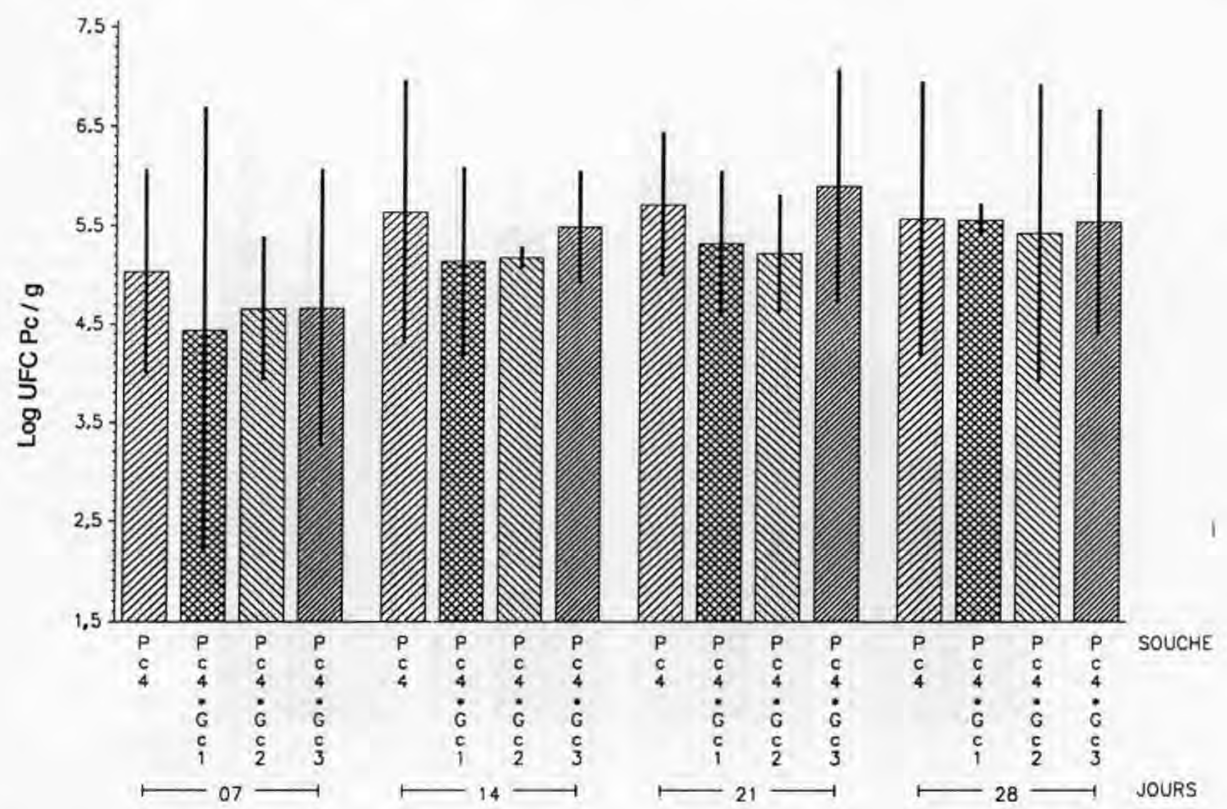

Fig 4. Évolution de la population de la souche de Penicillium camemberti 4 (Pc4) au cours de l'affinage des 4 fromages (Pc4 seul ou associé avec les 3 souches de Geotrichum candidum). Log UFC Pc/g: Log UFC Penicillium camembertipar gramme de fromage frais, moyenne des 4 répétitions de fabrication. Souche : combinaisons des souches de Penicillium camemberti et Geotrichum candidum. Jours : nombre de jours d'affinage. Les barres verticales représentent l'intervalle de confiance à $95 \%$.

Evolution of the population of the Penicillium camemberti strains 4 (Pc4) during the ripening of the 4 cheeses. Log UFC PC/g: Log CFU of Penicillium camemberti per $g$ of fresh cheese, mean of the 4 cheese making replicates. Souche: Penicillium camemberti and Geotrichum candidum strain. Jours: Number of ripening days. The vertical line represents the confidence interval at the level of $95 \%$.

14,21 et 28 jours (fig 5 ). Seuls les prélèvements réalisés à 7 jours sont significativement plus faibles $(P<0,05)$. Pour les 3 souches de Geotrichum candidum associées avec la souche Pc2, on observe une croissance du nombre d'UFC/g pendant les 9 premiers jours, avec une légère inhibition du développement au deuxième jour, certainement due à l'effet du salage. Le développement des souches de Geotrichum candidum diffère en fonction de la souche de Penicillium camemberti qui lui est associée. II existe une forte interaction entre les souches de Penicillium camemberti et de
Geotrichum candidum. En effet, quelle que soit la souche de Geotrichum candidum, le nombre d'UFC/g, en fin d'affinage, est significativement plus important lorsque ce champignon est associé avec la souche Pc3.

Contrairement aux produits ensemencés avec $5 \%$ de Geotrichum candidum, les produits ensemencés avec $1 \%$ de Geotrichum candidum n'ont pas donné de défaut de surface de type "peau de crapaud". Certains de ces derniers avaient cependant un aspect de surface plus "visqueux" que la normale. Enfin, tous les produits ensemencés avec Geotrichum candidum ont un 


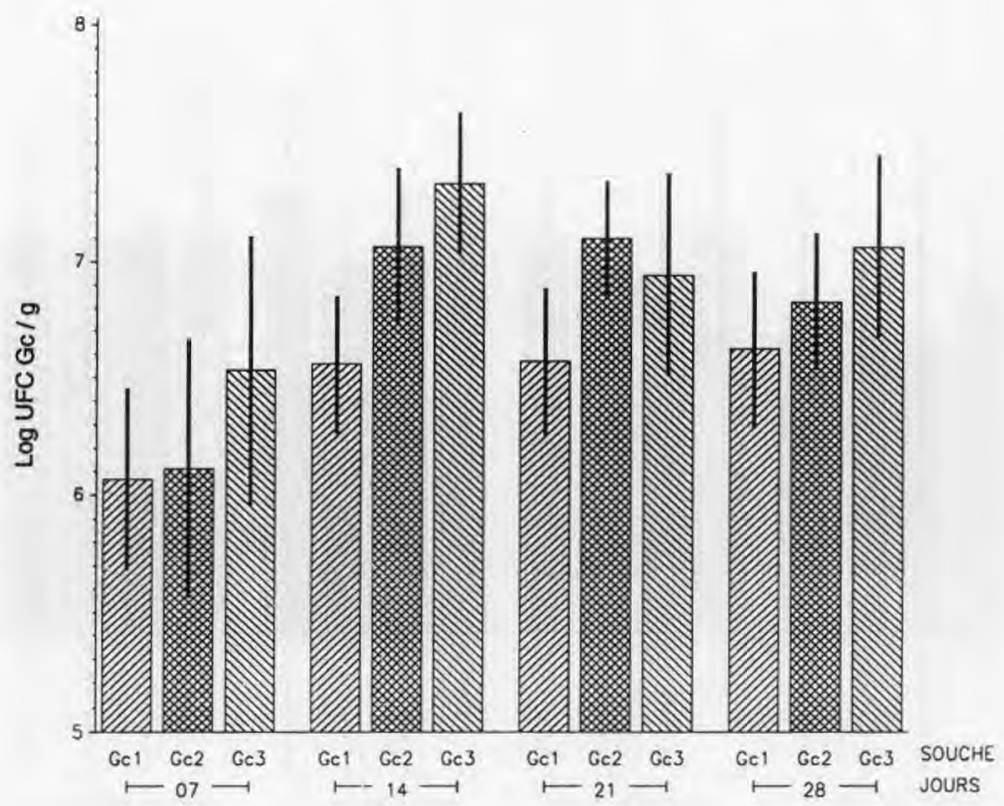

Fig 5. Évolution de la population des 3 souches de Geotrichum candidum au cours de l'affinage des fromages. Log UFC Gc/g: Log UFC Geotrichum candidum par gramme de fromage frais, moyenne des 4 produits fabriqués 4 fois avec Geotrichum candidum, soit 16 mesures. Souche : souche de Geotrichum candidum. Jours : nombre de jours d'affinage. Les barres verticales représentent l'intervalle de confiance à $95 \%$.

Evolution of the population of the 3 Geotrichum candidum strains during cheeses ripening. Log UFC Gc/g: $\log$ CFU of Geotrichum candidum per $g$ of fresh cheese, mean of the 4 products and 4 cheese making replicates (16 measures). Souche: Geotrichum candidum strain. Jours: Number of ripening days. The vertical line represents the confidence interval at the level of $95 \%$.

aspect de surface moins feutrant, une croûte plus fine qu'en présence de Penicillium camemberti seul. Mourgues et al (1983) ont également observé ce type d'aspect de surface. Ces auteurs ont décrit ce phénomène comme une occupation du terrain par Geotrichum candidum, gênant l'implantation et le développement de Penicillium camemberti. Notre étude montre que ces 2 phénomènes ne semblent pas liés. Cependant, Mourgues et al (1983) n'ont pas utilisé les mêmes souches et le niveau d'ensemencement en Geotrichum candidum était plus important.

Des dénombrements effectués après filtration de l'échantillon sur toile à bluter ont montré que les UFC dénombrées sont des fragments mycéliens ainsi que des spores. Les spores de Penicillium camemberti n'apparaissent que sur les prélèvements effectués après 9 jours d'affinage. Cette méthode de dénombrement ne quantifie que les cellules revivifiables après broyage. Pourtant, même si elle ne donne qu'une sous-estimation de la biomasse, elle a le mérite d'être facile à mettre en œuvre et de ne nécessiter qu'une mise au point réduite.

Les méthodes basées sur le dosage des constituants de parois, telles que le dosage chimique de la glucosamine ou des hexosamines (Frankland et Lindley, 1978; Cousin et al, 1984 ; Lin et Cousin, 1985) ne don- 
nent également qu'une estimation de la biomasse. La teneur des composés dosés peut évoluer au cours de la croissance. De plus les constituants de parois ne sont pas spécifiques d'une espèce et sont présents sur les cellules mortes.

Les techniques basées sur une réaction antigène-anticorps offrent une plus grande spécificité d'espèce. Elles sont encore peu développées et utilisées essentiellement pour la détection des champignons contaminants de denrées alimentaires, et non pour leur quantification (Notermans et Heuvelman, 1985 ; Lin et al, 1986 ; Notermans et al, 1986 ; Kamphuis et al, 1989 ; Notermans et Kamphuis, 1990). La méthode développée par Frankland et al (1981), grâce à l'utilisation d'un antisérum conjugué à la fluorescéine-isothiocyanate, permet une quantification spécifique de Mycena galopus. II existe cependant des limites à cette technique. La réaction a lieu, en effet, indifféremment avec les cellules vivantes et les cellules mortes. De plus, il n'existe pas, sur le marché, d'antisérum dirigé contre Penicillium camemberti ou Geotrichum candidum. La production de ces antisérums, chez le lapin, serait lourde à mettre en œuvre.

\section{CONCLUSION}

Le temps de broyage, la vitesse de rotation du broyeur et la dilution permettant une homogénéisation correcte de l'échantillon n'ont pas d'effet significatif sur le nombre d'UFC. Les conditions moyennes de $25 \mathrm{~s}$ à $18000 \mathrm{rpm}$ ont donc été retenues pour cette étude. Sur des cultures en milieu liquide, le nombre d'UFC estimé par cette méthode est corrélé de façon hautement significative à la teneur en matière sèche des cultures.

Sur les fromages expérimentaux de type camembert, nous avons pu observer que Geotrichum candidum se développe dès les premiers jours d'affinage, malgré l'effet inhibiteur du salage, avant que la croissance de Penicillium camemberti ne démarre. Au $14^{\mathrm{e}}$ jour d'affinage, cette population a atteint son maximum. La croissance de Penicillium camemberti ne semble pas, au vu de nos résultats, être gênée par la présence de Geotrichum candidum au niveau d'ensemencement de $1 \%$. Cette croissance ne débute qu'après le $7^{e}$ jour d'affinage et le nombre de cellules revivifiables reste constant à partir du $14^{\mathrm{e}}$ jour d'affinage.

La méthode de dénombrement mise au point et utilisée lors de cette étude ne quantifie que les cellules revivifiables après broyage de l'échantillon. Le nombre d'UFC que nous obtenons est un mode d'expression de la biomasse vivante sur le fromage, elle ne tient pas compte de l'activité enzymatique de la biomasse. La biomasse non revivifiable et les cellules lysées peuvent jouer un rôle non négligeable dans les activités métaboliques, par les enzymes libérées dans le milieu.

\section{REMERCIEMENTS}

Les auteurs remercient tout particulièrement : l'équipe du laboratoire de développement de Sanofi Bio-industries, division Cultures \& enzymes, pour la production des souches; $M$ Bigret et $P$ Schlich pour leur assistance scientifique ; G Mauvais et $\mathrm{G}$ Pitel pour leur participation technique ; la société Sanofi Bio-Industries, division Cultures \& enzymes, le ministère de l'Enseignement supérieur et de la Recherche ainsi que la région Bourgogne pour leur soutien financier.

\section{RÉFÉRENCES}

Adda J, Gripon JC, Vassal L (1982) The chemistry of flavor and texture generation in cheese. Food Chem 9, 115-129

Cerning J, Gripon JC, Lamberet G, Lenoir J (1987) Les activités biochimiques des Penicillium utilisés en fromagerie. Lait 67, 3-39

Cousin MA, Zeidler CS, Nelson PE (1984) Chemical detection of mold in processed foods. $J$ Food $\mathrm{Sci}$ $49,439-445$ 
Frankland JC, Lindley DK (1978) A comparison of two methods for the estimation of mycelial biomass in leaf litter. Soil Biol Biochem 10, 323-333

Frankland JC, Bailey AD, Gray TRG, Holland AA (1981) Development of an immunological technique for estimating mycelial biomass of Mycena galopus in leaf litter. Soil Biol Biochem 13, 87-92

Goupy J (1988) La méthode des plans d'expériences, optimisation du choix des essais et de l'interprétation des résultats. Dunod, Paris

Guéguen M (1984) Contribution à la connaissance de Geotrichum candidum et notamment de sa variabilité. Conséquences pour l'industrie fromagère. Thèse de Doctorat d'État, Caen

Guéguen M, Schmidt JL (1992) Les levures Geotrichum candidum. In: Les groupes microbiens d'intérêt laitier (Hermier J, Lenoir J, Weber F, eds). Cepil, Paris, $165-219$

Jarvis B, Seiler DAL, Ould AJL, Williams AP (1983) Observations on the enumeration of moulds in food and feedingstuffs. J App/ Bacteriol 55, 325-336

Jean M (1989) Staphylococcus aureus dans le "camembert de Normandie". Origine, comportement et production d'entérotoxines. Thèse de Doctorat, Caen

Kamphuis HJ, Notermans S, Veeneman GH, Van Boom $\mathrm{JH}$, Rombouts FM (1989) A rapid and reliable method for the detection of molds in foods: using the latex agglutination assay. J Food Prot 52, 244-247

Lenoir J, Auberger B (1966) Contribution à l'étude de la flore microbienne du fromage de type camembert. XVIle Congr Int Lait, Munich, Vol D 595-602

Lin $\mathrm{HH}$, Cousin MA (1985) Detection of mold in processed foods by high performance liquid chromatography. J Food Prot 48, 671-678
Lin HH, Lister RM, Cousin MA (1986) Enzyme-linked immunosorbent assay for detection of mold in tomato puree. J Food Sci 51, 180-192

Molimard P, Lesschaeve I, Bouvier I, Vassal L, Schlich P, Issanchou S, Spinnler HE (1994) Amertume et fractions azotées de fromages à pâte molle de type camembert : rôle de l'association de Penicillium camemberti avec Geotrichum candidum. Lait 74, 361-374

Mourgues R, Bergère JL, Vassal L (1983) Possibilité d'améliorer les qualités organoleptiques des fromages de camembert grâce à l'utilisation de Geotrichum candidum. Tech Lait 978, 11-15

Notermans S, Heuvelman CJ (1985) Immunological detection of moulds in food by using the enzymelinked immunosorbent assay (Elisa); preparation of antigens. Int J Food Microbiol 2, 247-258

Notermans S, Kamphuis H (1990) Detection of moulds in food by latex agglutination: a collaborative study. Food Agric Immunol 2, 37-46

Notermans S, Heuvelman CJ, Van Egmond HP, Paulsch WE, Besling JR (1986) Detection of mold in food by enzyme-linked immunosorbent assay. J Food Prot 49, 786-791

Ribadeau-Dumas B (1984) Maîtrise de l'affinage des fromages de type camembert. Lait 64, 448-468

Richard J, Zadi M (1983) Inventaire de la flore bactérienne dominante des camemberts fabriqués avec du lait cru. Lait 63, 25-42

SAS Institute Inc (1989) SAS/STAT ${ }^{*}$ user's guide. Version 6, Fourth Edn Vol 1 and 2, SAS Institute Inc, Cary, NC, États-Unis

Tolle A, Otte I, Shereng G, Heeschen N (1980) On the microflora of camembert cheese. Milchwissenschaft $35,21-25$ 